Copyright (C 2014 IEEE. Personal use of this material is permitted. Permission from IEEE must be obtained for all other uses, in any current or future media, including reprinting/republishing this material for advertising or promotional purposes, creating new collective works, for resale or redistribution to servers or lists, or reuse of any copyrighted component of this work in other works. 


\section{Steady State Analysis of a Novel Single Phase Induction Generator for Renewable Energy Conversion}

\author{
Diana Liyanage \\ Department of Electrical and Computer Engineering \\ Curtin University \\ Perth, Australia \\ diana.hikkaduw@postgrad.curtin.edu.au
}

\begin{abstract}
This paper presents the equivalent circuit and steady state behaviour of a recently introduced single phase generator configuration of a three phase squirrel cage induction machine. One winding of the three phase machine is used for real and reactive power control of the machine while remaining two windings are connected in series to form the output terminals to which the variable consumer load and a fixed excitation capacitor are connected. Starting from abc reference frame model, the paper derives dynamic equations of the system in both $\alpha-\beta$ and $d-q$ reference frames. Complete set of steady state equations are then derived in $\alpha-\beta$ reference frame model before proposing a novel steady state equivalent circuit. The steady state behaviour of the machine is analysed using Matlab Simulink under different conditions of load, rotor speed, excitation capacitance and voltage applied to the controlled winding. Comparison of the steady state values obtained from transient model and respective results obtained from the equivalent circuit shows the accuracy of the derived steady state model.
\end{abstract}

Index Terms- Induction Generator, Steady State Model, Equivalent Circuit.

\section{NOMENCLATURE}

$\theta_{\mathrm{r}} \quad:$ Angle between stator phase a and rotor phase a with respect to stator phase a in rad.

$\theta \quad:$ Angle between stator phase a and d-axis in rad.

$\delta \quad: \quad$ : Angle between d-axis and rotor phase a in rad.

$\omega \quad:$ Speed of dq frame in $\mathrm{rad} / \mathrm{s}$

$\omega_{\mathrm{r}} \quad:$ Angular rotor speed in electrical $\mathrm{rad} / \mathrm{s}$

$\omega_{\mathrm{m}} \quad:$ Angular rotor speed in mechanical $\mathrm{rad} / \mathrm{s}$

$\mathrm{P} \quad$ : Number of poles

$\varphi_{\mathrm{s}}, \varphi_{\mathrm{r}} \quad$ : Stator Flux, Rotor Flux

$\varphi_{\mathrm{a}}, \varphi_{\mathrm{b}}, \varphi_{\mathrm{c}} \quad$ : Flux in stator phase $\mathrm{a}, \mathrm{b}$ and $\mathrm{c}$ respectively.

$\mathrm{V}_{\mathrm{sa}}, \mathrm{V}_{\mathrm{sb}}, \mathrm{V}_{\mathrm{sc}}$ : Stator Voltages in phase $\mathrm{a}, \mathrm{b}$ and c respectively in Volts.

$\mathrm{V}_{\mathrm{ra}}, \mathrm{V}_{\mathrm{rb}}, \mathrm{V}_{\mathrm{rc}}$ : Rotor Voltages in phase $\mathrm{a}, \mathrm{b}$ and c respectively in Volts.

This work was supported in part by Australian Postgraduate Award offered to D. Liyanage.

\author{
Sumedha Rajakaruna \\ Department of Electrical and Computer Engineering \\ Curtin University \\ Perth, Australia \\ s.rajakaruna@curtin.edu.au
}

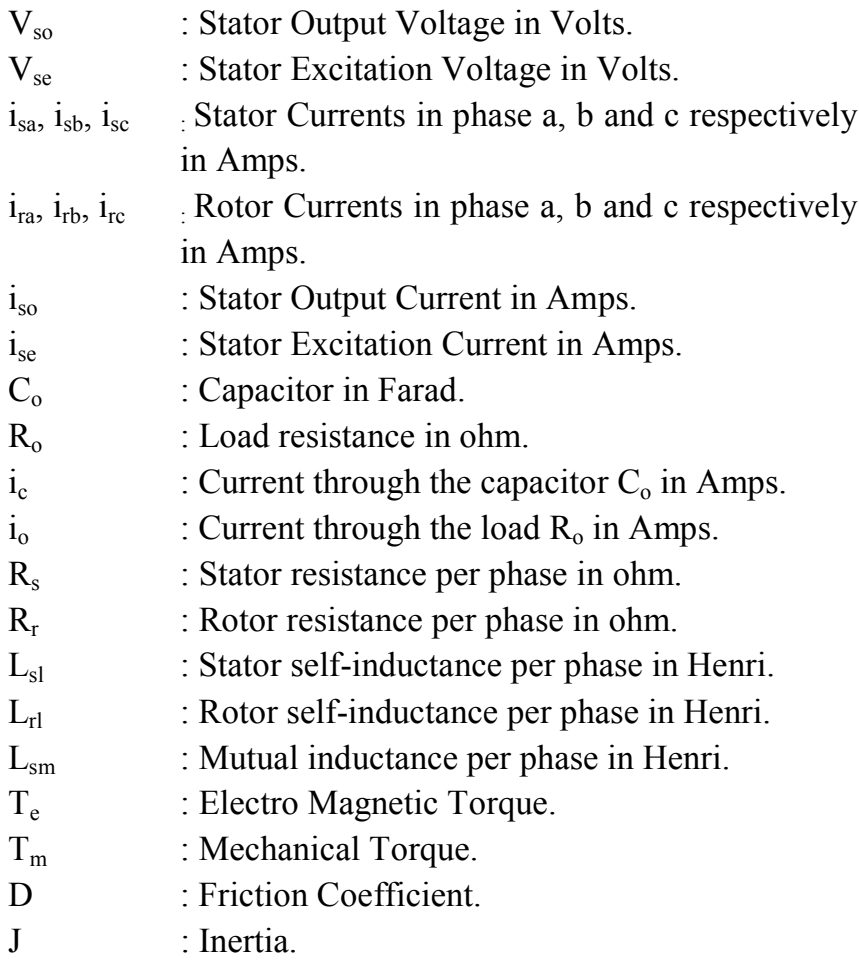

\section{INTRODUCTION}

The rapid depletion of the conventional fossil energy sources such as coal, oil and natural gas and the rising concern over the global warming has forced the governments all over the world to focus on the power generation using non-conventional energy sources such as wind, hydro and solar in an environmentally friendly manner [1], [2]. In both micro-hydro and wind power generation three phase induction generators are more popular due to their low unit cost, smaller size and easy maintenance [3][5]. Small scale wind energy generation systems are widely used in rural area where the three phase electricity supply may not be available. Electricity generation using single phase induction machines of the power ratings above $3 \mathrm{~kW}$ is less popular due to its disadvantages of heavy weight, high unit cost, bigger size and less availability [6], [7]. The single 
phase operation of three phase induction machines is preferred since they can overcome the above disadvantages. Among the introduced topologies of single phase electricity generation using three phase induction machine, Madawala et al [8] recently presented a topology that has better control of output voltage and frequency. In this configuration, two of the three windings are connected in series to form the output terminals to which the variable load impedance and a fixed excitation capacitor are connected in parallel. The remaining winding is used to control the real and reactive power balance in the system through a bidirectional dc-ac power converter. An Energy Storage System (ESS) is required on the dc side of the power converter to supply or absorb any deficit energy requirement of the system during periods where available renewable energy is low or absorb any excess energy production during high renewable energy condition so that the load demand is met at all times and the frequency is maintained at the rated value. The converter also varies the reactive power supplied to the machine such that the load voltage is maintained at its rated value.

The dynamic behaviour of this generator has been studied in the literature [9], [10] but the steady-state model is yet to be developed. This paper not only derives the steady state equations but also develops an equivalent circuit to predict the steady state behaviour. The paper analyses the steady state behaviour under different operating conditions using the developed steady state model and simulated using Matlab Simulink. These results are verified by comparing with the steady state results obtained from the already verified transient model of the generator under the same operating conditions.

\section{GENERATOR CONFIGURATION}

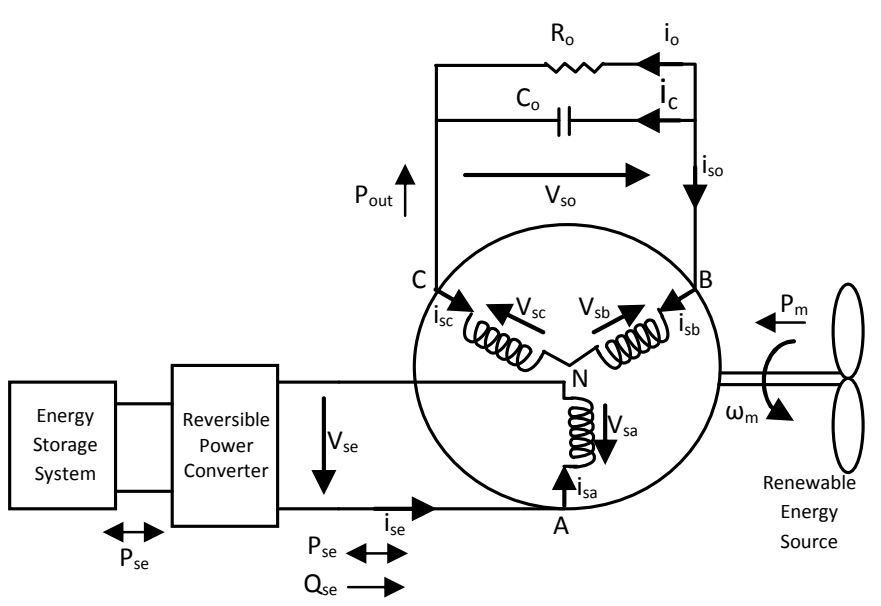

Fig. 1. Schematic diagram of the single phase IG

The generator phase ' $a$ ' is used as the excitation control winding and connected to the power converter. The ESS is connected at the dc side of the power converter. The generator phase $\mathrm{b}$ and $\mathrm{c}$ are connected in series to form the output winding and their terminals are connected to the variable load $R_{0}$. The fixed excitation capacitor $C_{0}$ is connected in parallel with the variable load. The schematic diagram of this generator configuration is shown in Fig. 1.

\section{DYNAMIC EQUATIONS}

\section{A. abc frame model}

The excitation control voltage and the output voltage can be presented by (1) [9].

$\left[\begin{array}{c}V_{s e} \\ V_{s o}\end{array}\right]=\left[\begin{array}{cc}R_{s} & 0 \\ 0 & 2 R_{s}\end{array}\right]\left[\begin{array}{l}i_{s e} \\ i_{s o}\end{array}\right]+$

$\omega_{r} L_{s m}\left[\begin{array}{ccc}-\sin \theta_{r} & -\sin \left(\theta_{r}+2 \pi / 3\right) & -\sin \left(\theta_{r}-2 \pi / 3\right) \\ \sqrt{3} \cos \theta_{r} & \sqrt{3} \cos \left(\theta_{r}+2 \pi / 3\right) & \sqrt{3} \cos \left(\theta_{r}-2 \pi / 3\right)\end{array}\right]\left[\begin{array}{l}i_{r a} \\ i_{r b} \\ i_{r c}\end{array}\right]$

$+\left[\begin{array}{cc}\left(L_{s l}+L_{s m}\right) & 0 \\ 0 & 2\left(L_{s l}+3 / 2 L_{s m}\right)\end{array}\right] \frac{d}{d t}\left[\begin{array}{l}i_{s e} \\ i_{s o}\end{array}\right]+$

$L_{s m}\left[\begin{array}{ccc}\cos \theta_{r} & \cos \left(\theta_{r}+2 \pi / 3\right) & \cos \left(\theta_{r}-2 \pi / 3\right) \\ \sqrt{3} \sin \theta_{r} & \sqrt{3} \sin \left(\theta_{r}+2 \pi / 3\right) & \sqrt{3} \sin \left(\theta_{r}-2 \pi / 3\right)\end{array}\right] \frac{d}{d t}\left[\begin{array}{c}i_{r a} \\ i_{r b} \\ i_{r c}\end{array}\right]$

The rotor voltages in phase $\mathrm{a}, \mathrm{b}$ and $\mathrm{c}$ are equal to zero in squirrel cage machine and presented in (2) [9].

$\left[\begin{array}{l}0 \\ 0 \\ 0\end{array}\right]=\omega_{r} L_{s m}\left[\begin{array}{cc}-\sin \theta_{r} & \sqrt{3} \cos \theta_{r} \\ -\sin \left(\theta_{r}+2 \pi / 3\right) & \sqrt{3} \cos \left(\theta_{r}+2 \pi / 3\right) \\ -\sin \left(\theta_{r}-2 \pi / 3\right) & \sqrt{3} \cos \left(\theta_{r}-2 \pi / 3\right)\end{array}\right]\left[\begin{array}{l}i_{s e} \\ i_{s o}\end{array}\right]$

$+\left[\begin{array}{ccc}R_{r} & 0 & 0 \\ 0 & R_{r} & 0 \\ 0 & 0 & R_{r}\end{array}\right]\left[\begin{array}{l}i_{r a} \\ i_{r b} \\ i_{r c}\end{array}\right]$

$+L_{s m}\left[\begin{array}{cc}\cos \theta_{r} & \sqrt{3} \sin \theta_{r} \\ \cos \left(\theta_{r}+2 \pi / 3\right) & \sqrt{3} \sin \left(\theta_{r}+2 \pi / 3\right) \\ \cos \left(\theta_{r}-2 \pi / 3\right) & \sqrt{3} \sin \left(\theta_{r}+2 \pi / 3\right)\end{array}\right] \frac{d}{d t}\left[\begin{array}{c}i_{s e} \\ i_{s o}\end{array}\right]$

$+\left[\begin{array}{ccc}\left(L_{r l}+L_{r m}\right) & -\frac{1}{2} L_{r m} & -\frac{1}{2} L_{r m} \\ -\frac{1}{2} L_{r m} & \left(L_{r l}+L_{r m}\right) & -\frac{1}{2} L_{r m} \\ -\frac{1}{2} L_{r m} & -\frac{1}{2} L_{r m} & \left(L_{r l}+L_{r m}\right)\end{array}\right] \frac{d}{d t}\left[\begin{array}{c}i_{r a} \\ i_{r b} \\ i_{r c}\end{array}\right]$

The current through the resistive load is given by (3).

$i_{o}=V_{\text {so }} / R_{o}$

The current through the capacitor Co can be defined as the product of the capacitance and the time derivative of the output voltage.

$i_{c}=C_{o} d V_{s o} / d t$

The addition of $i_{o}$ and $i_{c}$ is equal to the negative value of the single-phase output current $i_{\text {so }}$ which can be defined as (5).

$i_{s o}=-\left(i_{c}+i_{o}\right)$ 
The mechanical torque can be given by (6).

$T_{m}=T_{e}-J \frac{d \omega_{m}}{d t}-D \omega_{m}$

Where

$T_{e}=\frac{2}{\sqrt{3}}\left(\left(\left(\varphi_{a}-0.5 \varphi_{b}-0.5 \varphi_{c}\right) . i_{s o}\right)-\left(0.5\left(\varphi_{b}-\varphi_{c}\right) . i_{s e}\right)\right)$

\section{B. dq frame model}

Stator of the generator has two phases; the excitation control and the output which are aligned with the $\alpha$-axis and the $\beta$-axis respectively. Rotor has three phases which are $120^{\circ}$ apart from each other. Since the dealing with this multi-phases system is a complex exercise, three-phases of the rotor are transformed into two phases. If one phase of the rotor is assumed to be on d-axis which is $\theta$ angle apart from the $\alpha$-axis then the other phase is aligned on $q$-axis which is perpendicular to the d-axis. This transformation is shown in Fig. 2.

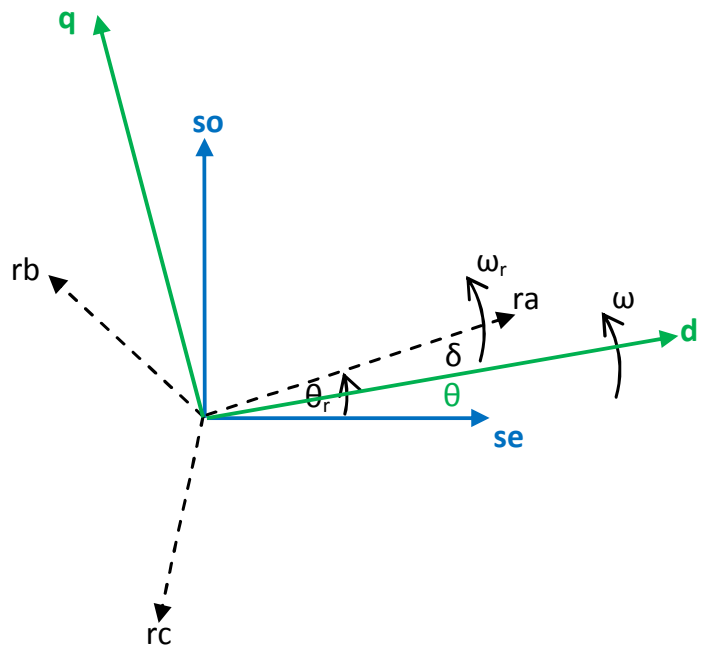

Fig. 2. dq transformation of rotor phase $a, b$ and $c$

Using the Park transformation, the rotor currents in phases a, $\mathrm{b}$ and $\mathrm{c}$ can be transformed into dq reference frame as in (8).

$\left[\begin{array}{l}i_{r d} \\ r_{r q}\end{array}\right]=\left(\frac{2}{3}\right)\left[\begin{array}{lll}\cos \delta & \cos \left(\delta+\left(\frac{2 \pi}{3}\right)\right) & \cos \left(\delta-\left(\frac{2 \pi}{3}\right)\right) \\ \sin \delta & \sin \left(\delta+\left(\frac{2 \pi}{3}\right)\right) & \sin \left(\delta-\left(\frac{2 \pi}{3}\right)\right)\end{array}\right]\left[\begin{array}{l}i_{r a} \\ i_{r b} \\ i_{r c}\end{array}\right]$

\section{C. $\alpha \beta$ frame model}

If the dq reference frame is assumed to be stationary, it will align with the $\alpha \beta$ reference frame. Then the rotor currents in $\alpha \beta$ reference frame can be written as below.

$\theta=0$

$\delta=\theta_{r}$

$\left[\begin{array}{l}i_{r \alpha} \\ r_{r \beta}\end{array}\right]=\left(\frac{2}{3}\right)\left[\begin{array}{ccc}\cos \theta_{r} & \cos \left(\theta_{r}+\left(\frac{2 \pi}{3}\right)\right) & \cos \left(\theta_{r}-\left(\frac{2 \pi}{3}\right)\right) \\ \sin \theta_{r} & \sin \left(\theta_{r}+\left(\frac{2 \pi}{3}\right)\right) & \sin \left(\theta_{r}-\left(\frac{2 \pi}{3}\right)\right)\end{array}\right]\left[\begin{array}{c}i_{r a} \\ i_{r b} \\ i_{r c}\end{array}\right]$
The excitation control voltage, generator output voltage, rotor voltages in phase $\alpha$ and $\beta$ can be given by (12).

$\left[\begin{array}{c}V_{s e} \\ V_{s o} \\ 0 \\ 0\end{array}\right]=$

$\left[\begin{array}{cccc}R_{s} & 0 & 0 & 0 \\ 0 & 2 R_{s} & 0 & 0 \\ 0 & \sqrt{3} L_{s m} \omega_{r} & R_{r} & \omega_{r}\left(L_{r l}+3 L_{s m} / 2\right) \\ -L_{s m} \omega_{r} & 0 & -\omega_{r}\left(L_{r l}+3 L_{s m} / 2\right) & R_{r}\end{array}\right]\left[\begin{array}{l}i_{s e} \\ i_{s o} \\ i_{r \alpha} \\ i_{r \beta}\end{array}\right]+$
$\left[\begin{array}{cccc}\left(L_{s l}+L_{s m}\right) & 0 & 3 L_{s m} / 2 & 0 \\ 0 & \left(2 L_{s l}+3 L_{s m}\right) & 0 & 3 \sqrt{3} L_{s m} / 2 \\ L_{s m} & 0 & \left(L_{r l}+3 L_{s m} / 2\right) & 0 \\ 0 & \sqrt{3} L_{s m} & 0 & \left(L_{r l}+3 L_{s m} / 2\right)\end{array}\right] *$

$\frac{d}{d t}\left[\begin{array}{l}i_{s e} \\ i_{s o} \\ i_{r \alpha} \\ i_{r \beta}\end{array}\right]$

The electromagnetic torque can be re-written as in (13).

$T_{e}=\left(\frac{P}{2}\right) L_{m}\left(\sqrt{3} i_{s o} i_{r \alpha}-i_{s e} i_{r \beta}\right)$

\section{STEADY EQUATIONS}

Equation (12) gives the stator and rotor voltages in $\alpha \beta$ frame with $d / d t$ terms. Replacing $d / d t$ terms by $j \omega_{1}$ the following steady state equations can be obtained.

$V_{s e}=R_{s} i_{s e}+\left(L_{s l}+L_{s m}\right) j \omega_{1} i_{s e}+\left(\frac{3}{2}\right) L_{s m} j \omega_{1} i_{r \alpha}$
$V_{s o}=2 R_{s} i_{s o}+\left(2 L_{s l}+3 L_{s m}\right) j \omega_{1} i_{s o}+\left(\frac{3 \sqrt{3}}{2}\right) L_{s m} j \omega_{1} i_{r \beta}$

$0=L_{s m} j \omega_{1} i_{s e}+\sqrt{3} L_{s m} \omega_{r} i_{s o}+\left(L_{r l}+\left(\frac{3}{2}\right) L_{s m}\right) \omega_{r} i_{r \beta}+$

$\left(R_{r}+\left(L_{r l}+\left(\frac{3}{2}\right) L_{s m}\right) j \omega_{1}\right) i_{r \alpha}$

$0=-L_{s m} \omega_{r} i_{s e}+\sqrt{3} L_{s m} j \omega_{1} i_{s o}-\left(L_{r l}+\left(\frac{3}{2}\right) L_{s m}\right) \omega_{r} i_{r \alpha}+$

$\left(R_{r}+\left(L_{r l}+\left(\frac{3}{2}\right) L_{s m}\right) j \omega_{1}\right) i_{r \beta}$

\section{EQUIVALENT CIRCUIT}

Equations (14)-(17) described the steady state behaviour of the generator are slightly modified to derive the equivalent circuit. First, (17) is multiplied by $\sqrt{3}$.

$0=-\sqrt{3} L_{s m} \omega_{r} i_{s e}+3 L_{s m} j \omega_{1} i_{s o}-\sqrt{3}\left(L_{r l}+\left(\frac{3}{2}\right) L_{s m}\right) \omega_{r} i_{r \alpha}+$

$\sqrt{3}\left(R_{r}+\left(L_{r l}+\left(\frac{3}{2}\right) L_{s m}\right) j \omega_{1}\right) i_{r \beta}$

By substituting $i_{r \alpha}=(2 / 3) i_{r \alpha}{ }^{\prime}$ and $i_{r \beta}=(2 / 3) i_{r \beta}{ }^{\prime}$ in (14), (15), (16) and (18), they can be re-written as in (19)(22).

$V_{s e}=R_{s} i_{s e}+\left(L_{s l}+L_{s m}\right) j \omega_{1} i_{s e}+L_{s m} j \omega_{1} i_{r \alpha}{ }^{\prime}$
$V_{s o}=2 R_{s} i_{s o}+\left(2 L_{s l}+3 L_{s m}\right) j \omega_{1} i_{s o}+3 L_{s m} j \omega_{1} i_{r \beta}{ }^{\prime}$ 
$0=L_{s m} j \omega_{1} i_{s e}+\sqrt{3} L_{s m} \omega_{r} i_{s o}+\left(\left(\frac{2}{\sqrt{3}}\right) L_{r l}+\sqrt{3} L_{s m}\right) \omega_{r} i_{r \beta}^{\prime}$

$+\left(\left(\frac{2}{3}\right) R_{r}+\left(\left(\frac{2}{3}\right) L_{r l}+L_{s m}\right) j \omega_{1}\right) i_{r \alpha}^{\prime}$

$0=-\sqrt{3} L_{s m} \omega_{r} i_{s e}+3 L_{s m} j \omega_{1} i_{s o}-\left(\left(\frac{2}{\sqrt{3}}\right) L_{r l}+\sqrt{3} L_{s m}\right) \omega_{r} i_{r \alpha}{ }^{\prime}+$

$\left(2 R_{r}+\left(2 L_{r l}+3 L_{s m}\right) j \omega_{1}\right) i_{r \beta}^{\prime}$

Stator and rotor voltages in $\alpha$-axis are given by (19) and (21) respectively. Similarly, stator and rotor voltages in $\beta$ axis are given by (20) and (22) respectively. Equation (19) together with (21) describes the equivalent circuit of $\alpha$-axis. The equivalent circuit of $\beta$-axis is described by (20) and (22). The equivalent circuit resulting from (19)-(22) is shown in Fig. 3.

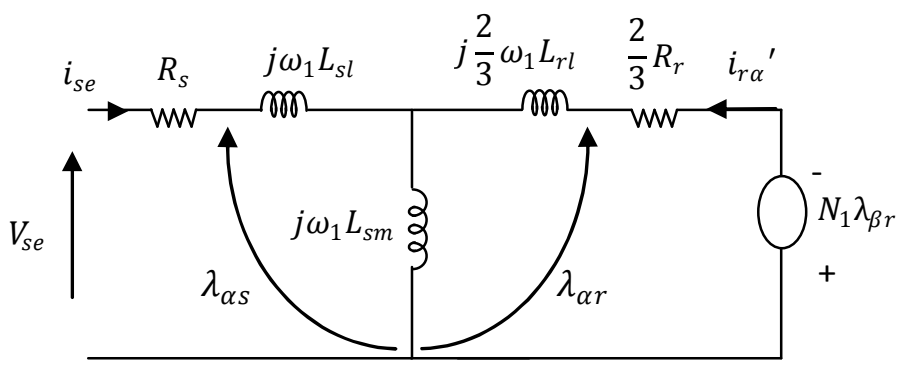

(a)

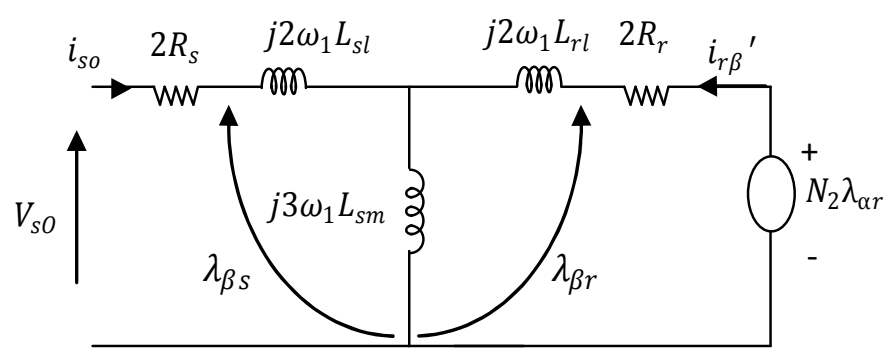

(b)

Fig. 3. Equivalent circuit of single phase generator (a) $\alpha$-axis (b) $\beta$-axis

Where;

$\lambda_{\beta r}=\left(3 L_{s m} i_{s o}+\left(2 L_{r l}+3 L_{s m}\right) i_{r \beta}^{\prime}\right) \omega_{r}$

$\lambda_{\alpha r}=\left(L_{s m} i_{s e}+\left(\left(\frac{2}{3}\right) L_{r l}+L_{s m}\right) i_{r \alpha}{ }^{\prime}\right) \omega_{r}$

$N_{2}=\frac{1}{N_{1}}=\sqrt{3}$

\section{COMPUTER SIMULATION}

The steady state behaviour of the novel generator configuration is analysed simulating the above mathematical model using Matlab Simulink. The User Defined Function Blocks in Matlab Simulink libraries are used to simulate these equations.

\section{RESULTS AND DISCUSSION}

The analyses of the steady state behaviour and the verification of the equivalent circuit of novel single phase induction generator were carried out for $2.2 \mathrm{~kW}$ three phase induction motor using Matlab Simulink. The parameters of the simulated induction motor are given in the Appendix. Rotor speed, excitation control voltage, fixed excitation capacitance and load impedance are considered as the operational parameters of the system. The effects of changing each of these parameters are studied separately in the following sections.

\section{A. Steady state behaviour at different rotor speeds}

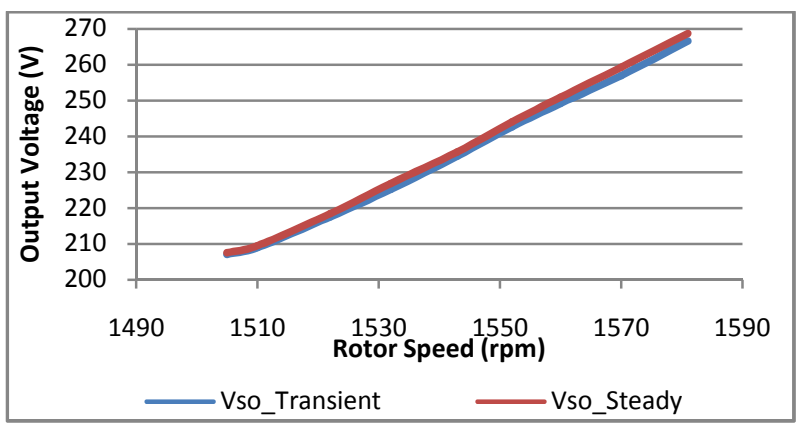

(a)

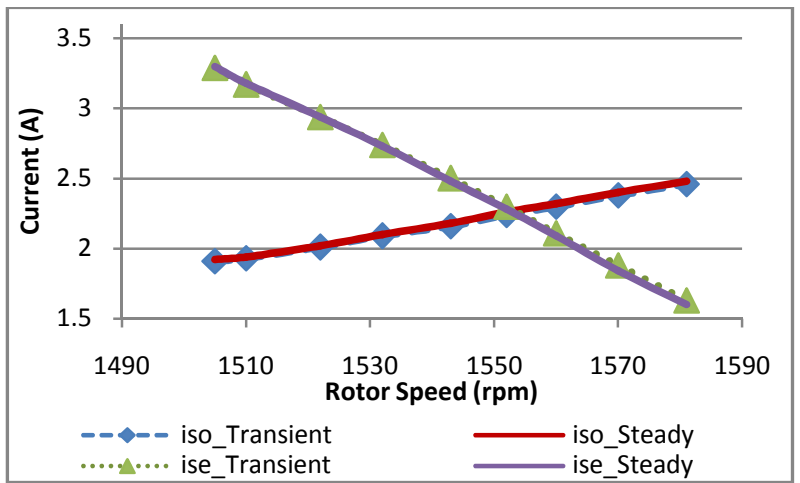

(b)

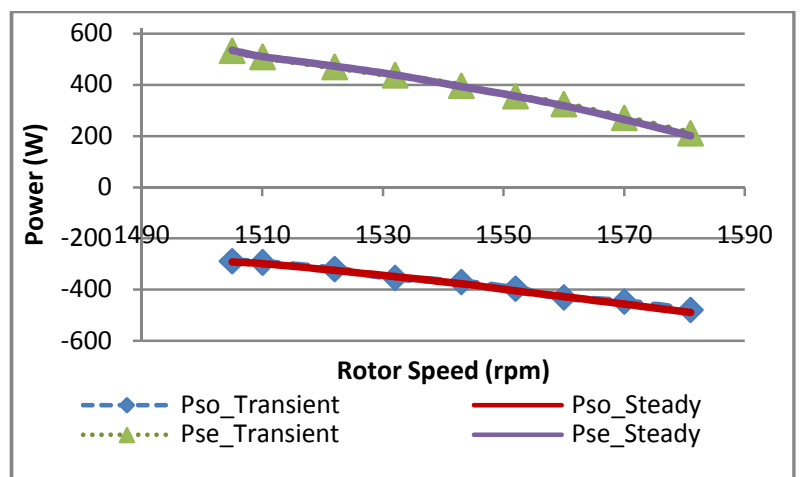

(c)

Fig. 4. Steady state results at different rotor speeds (a) Output Voltage (b) Output Current and Excitation Control Current (c) Output Power and Excitation Control Power 
The steady state behaviour of the induction generator at different rotor speeds was tested when other operational parameters were fixed at constant values. The load resistance and the capacitance were fixed at $147.5 \Omega$ and 20 $\mu \mathrm{F}$ respectively. A constant voltage of $210 \mathrm{~V}$ was supplied from the excitation control winding. The rotor speed was varied from $1505 \mathrm{rpm}$ to $1581 \mathrm{rpm}$. The relationships of voltage, current and power with rotor speed are shown in Fig. 4(a), (b) and (c) respectively.

Output voltage, current and power are directly proportional to the rotor speed. However excitation control current and power are inversely proportional to the rotor speed. Since the mechanical power of the generator system is directly proportional to the rotor speed, when the rotor speed is increased, the mechanical power increases too. The increment of the mechanical power increases the output power of the system. Therefore output voltage and current increase with the increasing rotor speed. This may cause to increase the reactive power in the system. Since the excitation control voltage is fixed, to maintain the reactive power balance in the system, the excitation control current decreases. Therefore the excitation control power also decreases with the increasing rotor speed.

\section{B. Steady state behaviour at different excitation control voltages}

Initially a voltage of $181 \mathrm{~V}$ was supplied from the excitation control winding. Then it was increased to $191.3 \mathrm{~V}, 200.2 \mathrm{~V}$, 209.2 V, 217.6 V, 226.2 V and up to 232 V. During the test, rotor speed, load resistance, capacitance were fixed at 1530 $\mathrm{rpm}, 128.7 \Omega$ and $20 \mu \mathrm{F}$ respectively. The effect of changing of excitation control voltage on output voltage is shown in Fig. 5(a). The relationships of output current and excitation control current with excitation control voltage are shown in Fig. 5(b). The behaviour of output power and excitation control power with the different excitation control voltages is presented in Fig. 5(c). When the excitation control voltage is increased, excitation control current and power increase. This power supply increases the output power of the generator. This causes to increase the output voltage and current of the generator as shown below.

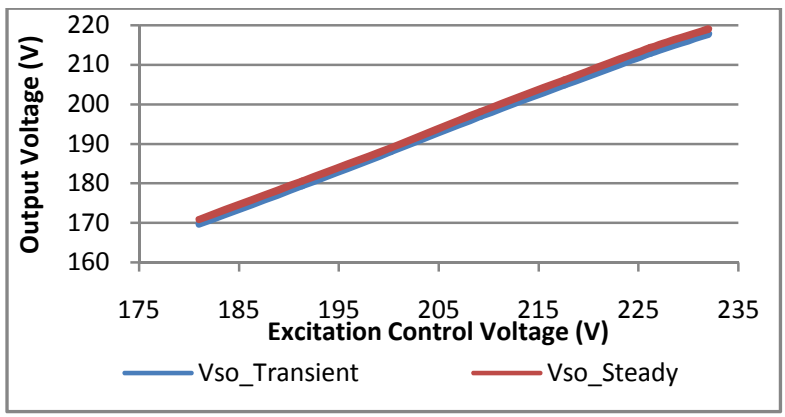

(a)

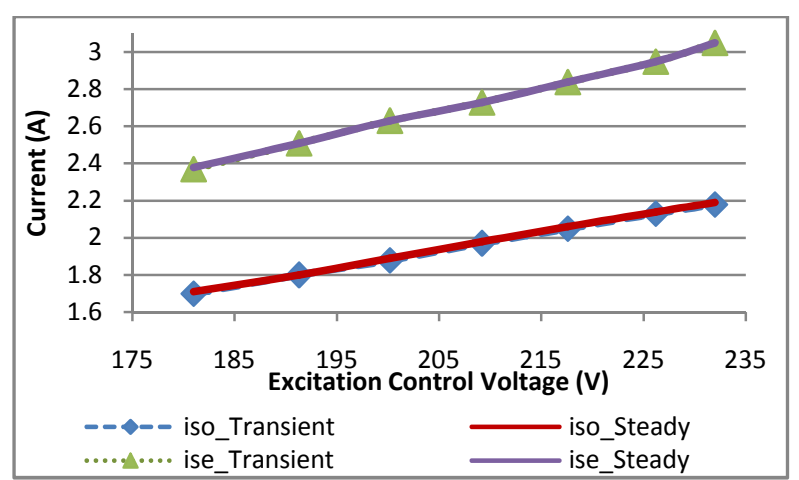

(b)

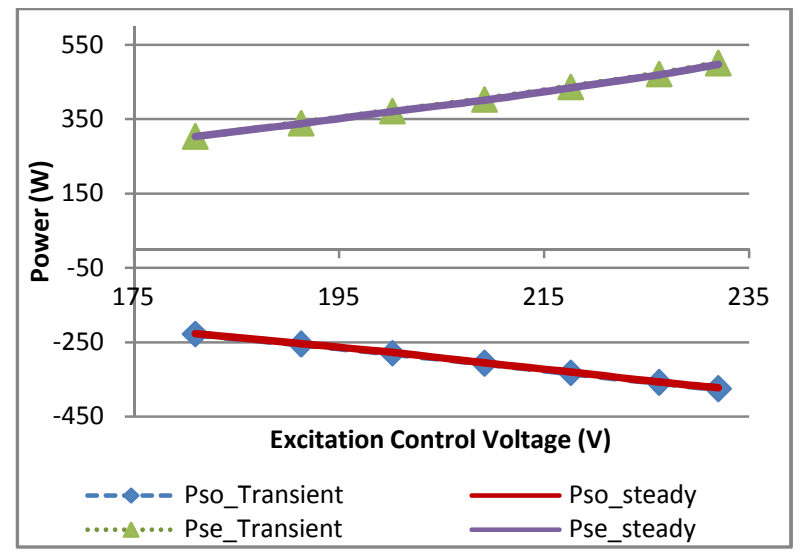

(c)

Fig. 5. Steady state results at different excitation control voltages (a) Output Voltage (b) Output Current and Excitation Control Current (c) Output Power and Excitation Control Power

\section{Steady state behaviour at different Capacitance}

The steady state behaviour of the induction generator at different capacitance values was tested under this section. The capacitance was changed from $10 \mu \mathrm{F}$ to $30 \mu \mathrm{F}$ in the steps of $5 \mu \mathrm{F}$. The excitation control voltage was $230 \mathrm{~V}$ and the load resistance was $128.7 \Omega$. The machine was operated at fixed rotor speed of $1530 \mathrm{rpm}$. Output power of the generator increases with the increasing capacitance until it reaches to the highest value at the capacitance about $20 \mu \mathrm{F}$. Then the output power decreases as the output voltage cannot further increase under the fixed excitation control voltage since it is unable to maintain the reactive power balance of the system. The excitation control power increases with the increasing capacitance. The behaviour of output power and excitation control power of the generator system is illustrated in Fig. 6(c). The relationship of the output voltage and the capacitance is shown in Fig. 6(a). Both the output current and the excitation control current are directly proportional to the capacitance as shown in Fig. 6(b). 


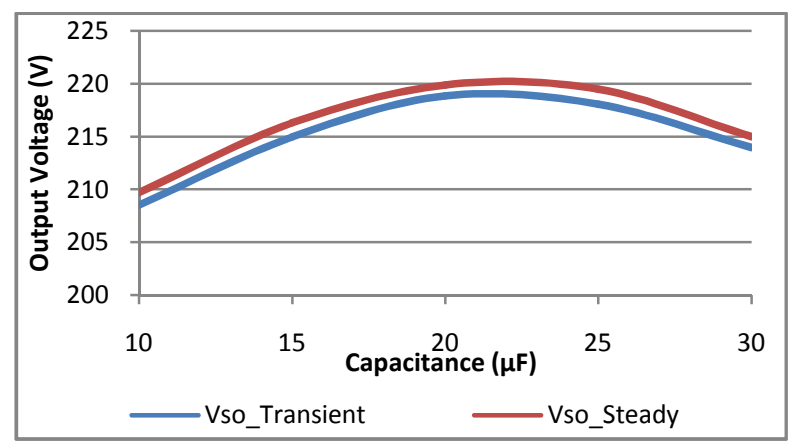

(a)

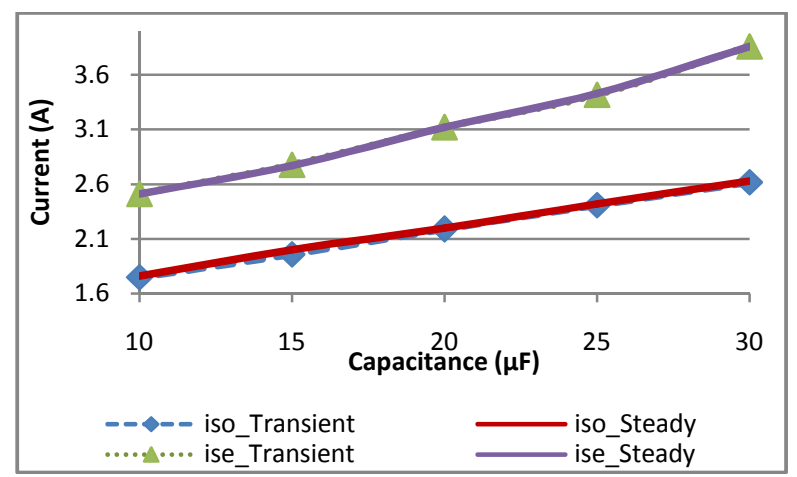

(b)

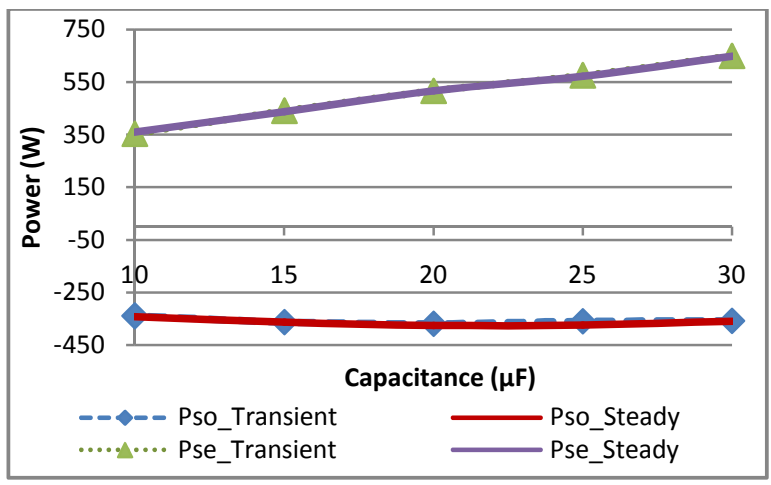

(c)

Fig. 6. Steady state results at different capacitance (a) Output Voltage (b) Output Current and Excitation Control Current (c) Output Power and Excitation Control Power

\section{Steady state behaviour at different Loads}

In this section, the steady state behaviour of the induction generator at different load resistance was analysed. The rotor speed and the capacitance were fixed at $1525 \mathrm{rpm}$ and $20 \mu \mathrm{F}$ respectively. A constant voltage of $210 \mathrm{~V}$ was supplied from the excitation control winding. The load resistance was varied from $94.3 \Omega$ to $175 \Omega$. The relationships of voltage, current, and power with the load resistance are shown in Fig. 7(a), (b) and (c) respectively. Output power increases when the load resistance is increased. Since the mechanical power is constant, the excitation control power increases to supply the output power requirement. To maintain the reactive power balance in the system, the excitation control current decreases at fixed excitation control voltage. When the load resistance is increased, both output voltage and output current increase to maintain the output power of the system.

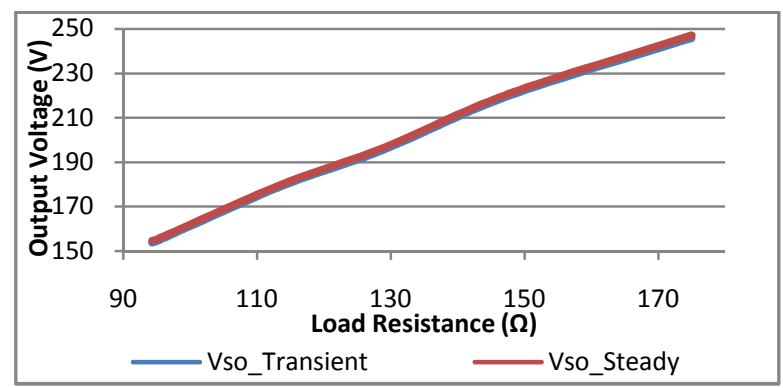

(a)

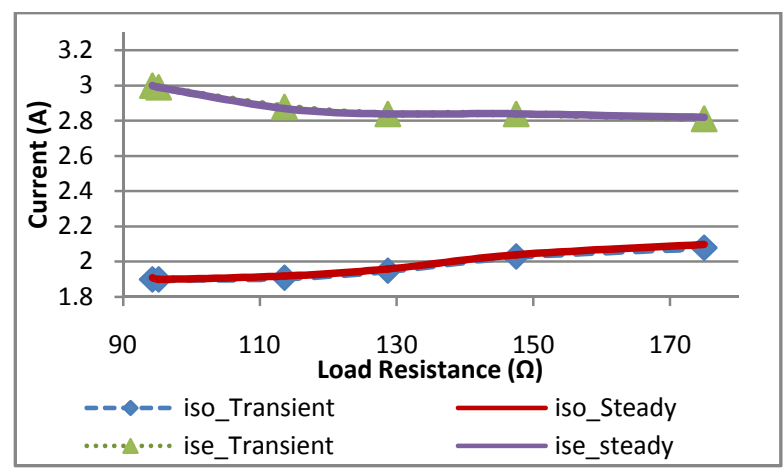

(b)

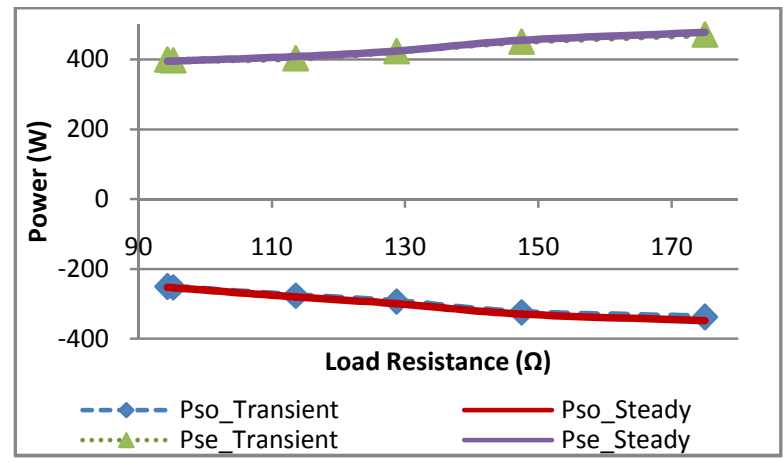

(c)

Fig. 7. Steady state results at different load resistance (a) Output Voltage (b) Output Current and Excitation Control Current (c) Output Power and Excitation Control Power

\section{CONCLUSION}

As shown in section VIII, the steady state behaviour of the newly introduced single phase induction generator configuration was analysed under four different scenarios. By studying these results it can be understood how the change of one operational parameter affects on the other variable parameters of the induction machine. The steady state results were obtained from two different models. One is the previously developed transient model of the machine. Other one is the steady state model presented in this paper. By comparing two sets of results, it can be clearly noticed 
that they match each other very well. It leads to the conclusion that the steady state equations and the steady state model presented in this paper are developed with a high degree of accuracy. Also it was demonstrated that the proposed equivalent circuit for the new single phase generator system is an easy to use tool in predicting the generator steady state behaviour accurately.

\section{APPENDIX}

The details of the machine are;

$2.2 \mathrm{~kW}, 3$-phase 4-pole, $50 \mathrm{~Hz}, 440 \mathrm{~V}$, delta connected

$\mathrm{R}_{\mathrm{s}}=11.313 \Omega, \mathrm{R}_{\mathrm{r}}=8.36 \Omega, \mathrm{L}_{\mathrm{sl}}=0.0632 \mathrm{H}, \mathrm{L}_{\mathrm{rl}}=0.0632 \mathrm{H}$, $\mathrm{L}_{\mathrm{sm}}=1.4491 \mathrm{H}, \mathrm{J}=0.07 \mathrm{~kg} . \mathrm{m}^{2}, \mathrm{D}=4.204 * 10^{-4} \mathrm{Nms}$

\section{REFERENCES}

[1]. J.M. Carrasco, L. G. Franquelo, J. T. Bialasiewicz, and E. Galvan, "Power electronics systems for the grid integration of renewable energy sources: A survey," IEEE Trans. Ind. Electron., vol. 53, no. 4, pp. 1002-1016, Jun. 2006.

[2]. C. Liu, K. T. Chau, and X. Zhang, "An efficient wind-photovoltaic hybrid generation system using doubly excited permanent magnet brushless dc machine," IEEE Trans. Ind. Electron., vol. 57, no. 3, pp. 831-839, Mar. 2010.

[3]. K. Idjdarene, D. Rekioua, T. Rekioua, A. Tounzi, "Performance of an Isolated Induction Generator Under Unbalanced Loads", IEEE Trans. on Energy Conversion, vol. 25, pp. 303-311, June 2010.

[4]. S.S. Murthy, "A novel self-induced self-regulated single phase induction generator. I. Basic system and theory", IEEE Trans. on Energy Conversion, vol. 8, pp. 377-382, Sep 1993.

[5]. D.K. Palwalia, S.P. Singh, "Design and implementation of induction generator controller for single phase self excited induction generator", in Conf. Rec. IEEE 3rd Conf. on Industrial Electronics and Applications, pp. 400-404, June 2008.

[6]. T.F. Chan, "Performance analysis of a three-phase induction generator connected to a singlephase power system", IEEE Trans. on Energy Conversion, vol. 13, pp. 205-213, Sep. 1998.

[7]. T. Fukami, M. Imamura, Y. Kaburaki, T. Miyamoto, "A New SelfRegulated Self-Excited Single-phase Induction Generator Using a Squirrel Cage Three-phase Induction Machine", Proc. Of the IEEE, vol. 1, pp. 308-312, Nov. 1995.

[8]. U.K. Madawala, T. Geyer, J.B. Bradshaw, D.M. Vilathagamuwa, "Modeling and Analysis of a Novel Variable-Speed Cage Induction Generator", IEEE Transaction on Industrial Electronics, Vol. 59, Issue: 2, pp. 1020- 1028, 2012.

[9]. Diana Liyanage, S. Rajakaruna, "Transient analysis of a single-phase variable speed cage induction generator with active excitation control" in Conf. Rec. IEEE Conf. on Power Engineering (AUPEC), Tasmania, pp. 1-6, 2013.

[10]. U. K. Madawala, D. Muthumani, "A novel variable speed cage induction generator", in Conf. Rec. IEEE ICSET on Sustainable Energy Technologies, pp. $1250-1255,2008$. 